\title{
Suelo, ejido y ciudad mexicana. Algunos apuntes para comprender su relación
}

\author{
Carlos FLORES \\ Área de Ciencias Sociales y Humanidades \\ Universidad Autónoma de Nayarit (México) \\ fcarlose@gmail.com
}

Recibido: 18-04-2015

Aceptado: 02-08-2015

\section{RESUMEN}

En el México posrevolucionario, dos discusiones marcarían su devenir: municipalismo y agrarismo. Aunque el municipio fue la base de la división territorial y administrativa del país, en la década del treinta del siglo pasado se inicia la repartición agraria bajo la fórmula del ejido. Su peculiar marco jurídico, sin embargo, enfrentaría a ambas instituciones posibilitando la instauración de gobiernos y autoridades paralelas. Si bien las contradicciones surgieron desde un inicio, sería con la institucionalización del planeamiento urbano del país en la década del setenta, cuando la lucha por el control y administración del territorio empieza a ser evidenciada. Con casi cuatro décadas de coexistencia, a pesar de reformas y modificaciones a sus legislaciones, ambas instancias continúan mostrándose incompatibles, en competencia y, en no pocas veces, en connivencia. El trabajo, y desde una posición histórica hermenéutica, busca reflexionar en dichas implicaciones y pretende abonar en su discusión y actualidad.

Palabras clave: ejido; municipio; planeamiento urbano; negociación; México.

\section{Land, Ejido, and Mexican city: Some Remarks to Understand their Relationship}

\begin{abstract}
In post-Revolutionary Mexico, two issues became pervasive: municipality and agrarianism. While municipality was the basis for the territorial and administrative division of the country, the thirties of the past century saw the beginning of the agricultural distribution based on the common land (ejido) formula. However, the particularities of its legal framework led to the confrontation between both institutions, enabling the founding of parallel governments and authorities. Although contradictions were present from the outset, it was the establishment of urban planning for the country in the sixties which exacerbated the fight for the control and administration of the land. After almost four decades of coexistence and despite the reforms and amends in their legal frameworks, both instances continue to be incompatible, in competition and, not seldom, in collusion. From a historical hermeneutic position, this work seeks to reflect upon their implications and intends to offer further insights into their discussion and current shape.
\end{abstract}

Key words: ejido; municipality; urban planning; negotiations; Mexico. 


\title{
Solo, ejido e cidade mexicana: alguns apontamentos para compreender sua relação
}

\begin{abstract}
RESUMO
No México pós-revolucionário, duas discussões marcariam seu devir: municipalismo e agrarismo. Ainda que o município fosse a base da divisão territorial e administrativa do país, na década de trinta do século passado, inicia-se a repartição agrária sob a fórmula do ejido. Seu peculiar marco jurídico, no entanto, enfrentaria a ambas as instituições, possibilitando a instauração de governos e autoridades paralelas. Conquanto as contradições tenham surgido desde o início, foi com a institucionalização do planejamento urbano do país da década de setenta que a luta pelo controle e pela administração do território começou a ser evidenciada. Com quase quatro décadas de coexistência, apesar de reformas e modificações em suas legislações, ambas as instâncias continuam se mostrando incompatíveis, em concorrência e, em não poucas vezes, em conivência. Este trabalho, desde uma posição histórica hermenêutica, procura refletir sobre as implicações desse processo e pretende aprofundar sua discussão e atualidade.
\end{abstract}

Palavras-chave: ejido; município; planejamento urbano; negociação; México.

\section{REFERENCIA NORMALIZADA}

Flores, Carlos (2015) "Suelo, ejido y ciudad mexicana. Algunos apuntes para comprender su relación". Geopolítica(s). Revista de estudios sobre espacio y poder, vol. 6, núm. 2, 201-224.

SUMARIO: Introducción. 1. El territorio sin planeamiento. 2. El planeamiento sin territorio. 3. Las prácticas sustitutas. A manera de conclusiones. Bibliografía.

[...] al municipio se le ha dejado una libertad muy reducida, casi insignificante; una libertad que no puede tenerse como tal porque sólo se ha concretado al cuidado de la población, al cuidado de la policía [...]

Heriberto Jara

59a. sesión del Constituyente, 24 de enero de 1917.

\section{Introducción}

Con una ascendencia del medievo castellano, como referente inmediato, el municipio en México contiene una alta tradición como organización territorial, forma de gobierno y administración local hasta nuestros días (Robles, 1993). En la lucha armada mexicana, aunque en menor intensidad que el agrarismo, el municipalismo formó parte de sus ideales, por lo que en la discusión posrevolucionaria, la disputa por el reparto del suelo enfrentaría a ambas instancias donde, finalmente, los agraristas excluyen a los municipalistas (Baitenmann, 2001). Esta primacía de lo agrario sobre lo municipal marcaría su relación hasta nuestros días. 
El enfrentamiento por el control del suelo entre ambos ámbitos no es nuevo. Desde la Colonia, las dos actividades que caracterizaban al suelo - sobre todo el urbano - fueron el tráfico y los usos no permitidos (Knowlton, 1988). El distingo de las operaciones urbanas lícitas de las ilícitas, sin embargo, a diferencia de lo mencionado por Leal Maldonado y García-Bellido (2003), en México se evidencia hasta la aparición no de Leyes Urbanas propiamente, sino de las Leyes Agrarias de principios del siglo pasado. Hubo de esperar poco más de seis décadas, con la promulgación de la Ley General de Asentamientos Humanos (LGAH) de 1977 —es decir, con la institucionalización del planeamiento en México-, para crear un marco regulatorio que escindiera las actividades territoriales urbanas legales de las ilegales.

Durante este más de medio siglo, como lo señala Baitenmann (2001), la relación entre los Núcleos Agrarios (NA) y los municipios nunca fue reglamentada, por lo que la sui generis autonomía otorgada a los ejidos en la gestión de su suelo, particularmente en aquellos que contienen un asentamiento humano dentro de su área y especialmente el que colinda con las ciudades, agudizó las contradicciones surgidas por la duplicidad de marcos jurídicos, instituciones, autoridades y criterios en su control y ordenamiento. De tal forma que se imposibilita entender - y planificarlas actuales ciudades mexicanas, si no se entiende este tipo de propiedad y sus relaciones.

En ese sentido, y desde una mirada histórica hermenéutica, el trabajo procura abonar en esta discusión. En una primer parte, luego de relatar sucintamente la instauración del suelo ejidal, se abordan algunas contradicciones surgidas en dicho evento. Una de ellas, y quizá la más representativa, refiere a la autonomía en la toma de decisiones en la gestión de su territorio. Esta contradicción jurídica, facilitó la duplicidad de instituciones, autoridades y criterios en su control y ordenamiento. La reforma agraria, también posibilitó la sobreposición, y enfrentamiento, de dos marcos jurídicos y valores culturales: el Agrícola y el Urbano. En una segunda parte, se analiza el surgimiento del planeamiento urbano territorial así como su institucionalización en el país. Se señala, que aunque la legislación que normaba la actividad y el reparto agrario tuvo una continua evolución, la legislación urbana apareció casi medio siglo después, por lo que su surgimiento, además de tardío, se da en un escenario en el cual los diversos fenómenos urbanos, particularmente los territoriales, estaban inmersos en una lógica distinta y en una multitud de leyes y enfoques ajenos a dicho marco jurídico. En una tercera, se identifican los mecanismos, que en la convivencia con los municipios, los NA han implementado para negociar y sobrevivir. Su comportamiento depende, principalmente, de sus condiciones geográficas y de sus características sociales de origen. En esta adaptación-evolución, y ya que su marco jurídico se los permite, de facto funcionan como autoridades sustitutas o paralelas a las municipales, horizontalizando la negociación lo que, de alguna forma, modifica la imagen que comparten tanto de Durand (1983) como Warman (1980) de históricos perdedores. Al final del texto, y a manera de genera- 
lizaciones, se esbozan cuatro elementos que deben considerarse para dilucidar la relación de los NA con los tres niveles de gobierno, emergiendo, y desde la intensa relación entre dichos elementos, como un cuarto nivel del poder en México.

\section{El territorio sin planeamiento}

En su mayoría encaminadas a la formación de la pequeña propiedad, durante algunos gobiernos posrevolucionarios se habían utilizado varias fórmulas para resolver el problema agrario (Montalvo Ortega, 1988). Paralelamente, y como antítesis latifundista, surge la institución reinterpretada y sui generis del ejido (Eckstein, 1966: 7). Esta, no obstante, hubo de acompañarse de múltiples y diversas discusiones $^{1}$ de índole político, cultural, ideológicas y doctrinarias, que desde mediados del siglo XIX - como el Proyecto de Leyes Agrarias de Severo Maldonado de 1873, hasta la Ley del 6 de enero de 1915-, fundamentaron el mito del México rural personificado en lo ejidal como institución (Hale, 1997).

Independientemente de su carga ideológica - y quizá por ello- en este surgimiento debe introducirse el tema del municipalismo como elemento catalizador y contraparte de esta lucha por el territorio. A lo largo de su instauración - $\mathrm{y}$ desde el siglo XVIII - , su autoridad —y su suelo — había sido diezmado (Robles, 1993; Gibson, 1967), por lo que la autonomía municipal, si bien no fue un aspecto central de la lucha armada, las consignas municipalistas - aunque paulatinamenteigualmente formaron parte de los ideales revolucionarios (Villar Calvo, 1998).

Municipalismo y Agrarismo se erigieron como las dos instancias que le otorgaron carácter e identidad al México posrevolucionario y que, sin embargo, como primer punto de quiebre, dice Baitenmann (2001) que emergieron incompatibles. De esta manera a lo largo de las discusiones posrevolucionarias, la disputa central es por la tierra y, la reforma agraria, culmina con la exclusión de los municipios y la institucionalización del ejido como su destinatario. Este predominio de lo agrario sobre lo municipal, como se ha dicho, acompañaría al quehacer territorial hasta nuestros días.

Desde su inicial idea hasta su establecimiento, la reforma agraria experimentó paulatinas modalidades. En todas estas propuestas, sin embargo, al NA -ejidal o comunal- se le preservó la capacidad de autogobierno a través de un marco jurídico propio que les concedía autonomía en la toma de decisiones e independencia en

\footnotetext{
${ }^{1}$ En la discusión de la carga ideológica del ejido, además de los trabajos de Eckstein (1966) y Hale (1997), se recomiendan — entre otros - las obras de Montalvo Ortega (1988), Mendieta y Nuñez (1946) y Mesa (1961). En su mayoría, sin embargo, hay un sesgo hacia la interpretación de un mito nacionalista en donde la noción de comunidad y la noción del calpulli indígena, están presentes.
} 
su gobierno interno. Además de la inalienabilidad, imprescriptibilidad ${ }^{2}$ e imposibilidad de embargo de su suelo (art. 73 LA); las canonjías incluirían la administración de su territorio y de su hacienda (art. 106 LFRA) y, durante un tiempo, la conformación de cuerpos armados de policía propia ${ }^{3}$, lo que los convertían de facto, según Wolf (1985), en una especie de Estado dentro de otro Estado.

Además de lo anterior, este suelo contiene otras singularidades. Debido a que en México, constitucionalmente, sólo se reconocen dos tipos de propiedad: la pública y la privada; coloquialmente - e incluso institucionalmente - a este tipo de suelo se le asignaría la imprecisa categoría de propiedad social. En su posible aclaración, Azuela de la Cueva (1999) establece que esta propiedad se define simultáneamente como propiedad privada y como propiedad común —o más precisamente corporativa- Por lo que en rigor, dice el autor, en México hay dos modalidades de propiedad privada: la privada individual y la privada comunal — que es la social一; es decir, la corporación (NA), es la propietaria de las tierras, y los campesinos que la forman, son titulares de una serie de derechos individuales. Esto, de forma alguna, coincide con un trabajo de Roger Bartra de 1976, el cual determina que la propiedad ejidal es una propiedad privada corporativizada (Pazos, 1991: 19). En otras palabras, y con todo lo que ello signifique, se trata de una propiedad privada no regida por el derecho común sino por las leyes agrarias.

Por otro lado, geográficamente, sus polígonos pueden ubicarse en distintos estados federativos o en distintos municipios. La no contigüidad, empero, no impide a los NA constituirse como unidades geográficas independientes. Por su parte, el destino de las tierras puede ser de tres tipos: para el asentamiento de la población - si lo hubiera - o parcelario urbano; para las parcelas agrarias y; para el uso común (Gráfico 1). Cada una con características diferenciadas pero modificables a partir de facultades de su máximo órgano interior de gobierno denominado Asamblea Ejidal, y que se contienen en los artículos 23 y 65 de la Ley Agraria:

Artículo 23. [...] Serán de la competencia exclusiva de la asamblea los siguientes asuntos:

$[\ldots]$

\footnotetext{
${ }^{2}$ No debe olvidarse que se han establecido varias modalidades para su prescripción, no obstante, en cualquiera de ellas, implica necesariamente un cambio de estatus: de propiedad ejidal a propiedad privada. Esta acción se conoce genéricamente como "desincorporación" y se consuma siempre que exista un Decreto de Autorización firmado por el Presidente de la República con su respectiva publicación en el Diario Oficial de la Federación. De esta manera, el territorio en cuestión, deja de sujetarse a las leyes agrarias para someterse al derecho común.

${ }^{3}$ Conocidas como Defensas Rurales, se trataba de "grupos armados formados por campesinos de ejidos y comunidades beneficiados por el reparto agrario. Cada ejido podía formar su propia defensa rural [...]" (Mendoza, 2002: 111).
} 
Gráfico 1. Distribución, localización y usos del suelo del Ejido de Los Mezquites

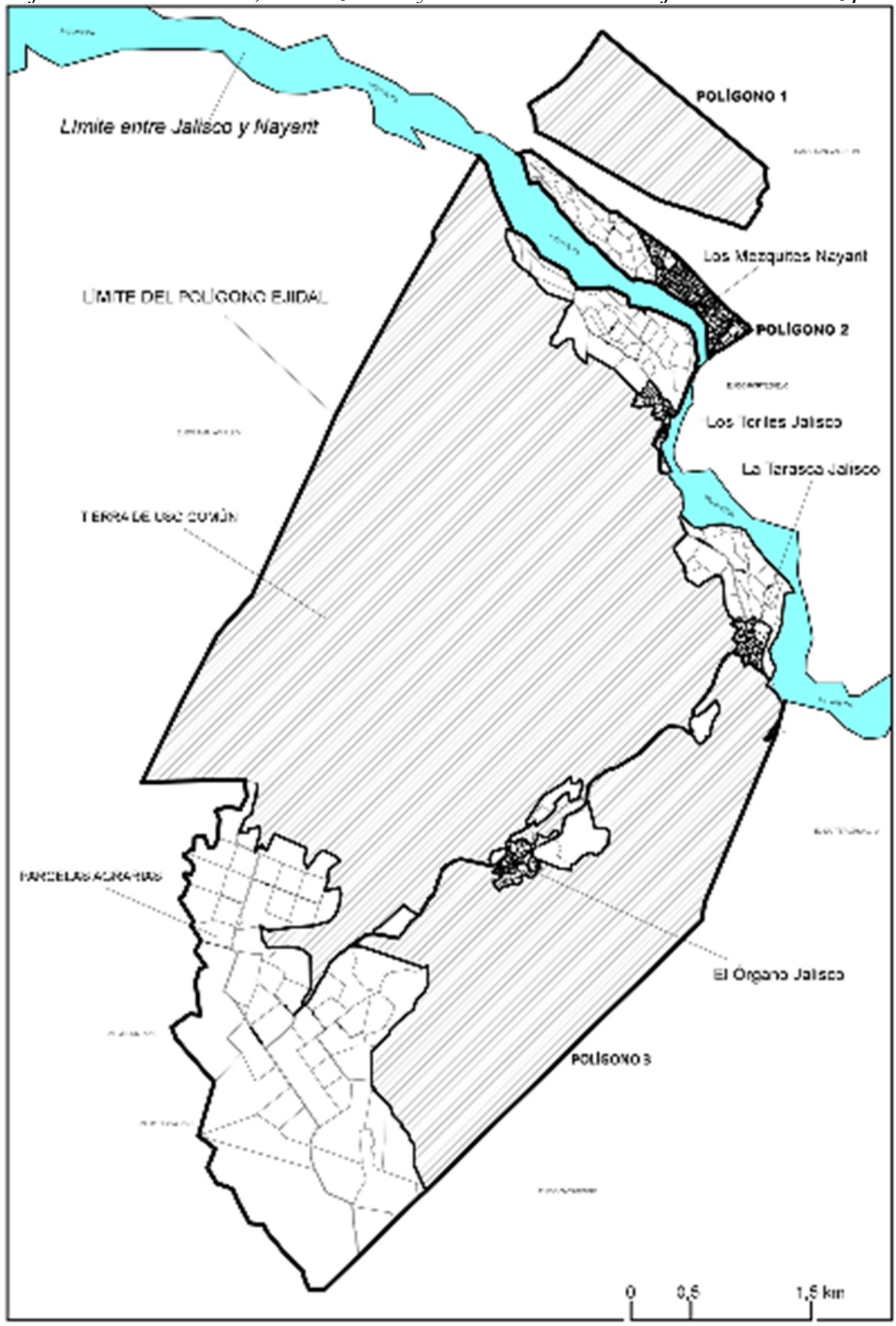

Fuente: elaboración propia. 
VII. Señalamiento y delimitación de las áreas necesarias para el asentamiento humano, fundo legal y parcelas con destino específico, así como la localización y relocalización del área de urbanización;

VIII. Reconocimiento del parcelamiento económico o de hecho y regularización de tenencia de posesionarios;

IX. Autorización a los ejidatarios para que adopten el dominio pleno sobre sus parcelas y la aportación de las tierras de uso común a una sociedad, en los términos del artículo 75 de esta ley;

X. Delimitación, asignación y destino de las tierras de uso común así como su régimen de explotación;

$[\ldots]$

Artículo 65. Cuando el poblado ejidal esté asentado en tierras ejidales, la asamblea podrá resolver que se delimite la zona de urbanización en la forma que resulte más conveniente ${ }^{4}$, respetando la normatividad aplicable y los derechos parcelarios. Igualmente, la asamblea podrá resolver que se delimite la reserva de crecimiento del poblado, conforme a las leyes de la materia.

Sería a partir la década del cuarenta, y hasta bien entrada la del noventa, cuando el Estado desarrolla la mayor carrera del reparto agrario bajo las cuatro ${ }^{5}$ modalidades que gradualmente se establecieron para ello. Como resultado, más de la mitad del suelo mexicano, incluyendo el inmediato a las principales ciudades y que contenía el histórico fundo ${ }^{6}$ de los municipios, se utilizó para la dotación ejidal (Contreras Valdez, 2001), de manera que aproximadamente el 51\% del territorio —algo así como 100 millones de hectáreas- pertenecen a los poco más de 31.990 NA con que cuenta el país ${ }^{7}$.

\footnotetext{
${ }_{5}^{4}$ La cursiva es mía.

5 1. Restitución; 2. Dotación; 3. Nuevos Centros de población y; 4. Ampliación. Denominados genéricamente como NA, se distinguen por la acción agraria que los origina. Los de la primera modalidad son NA Comunales o Comunidades Agrarias por lo que a sus miembros se les llama comuneros y se asocian a las comunidades indígenas originarias. Los constituidos por cualquiera de las otras tres acciones son los NA Ejidales y, a sus miembros, se les denomina ejidatarios. A estos últimos corresponde poco más del $80 \%$ de la totalidad del suelo social.

${ }^{6}$ El fundo, o por sus acepciones, fundo municipal o fundo legal, en la traducción Virreinal, se refería al "asiento de la población" y en ella se incluían, además de suelo para el crecimiento, las casas de los moradores, los edificios públicos, los mercados y las escuelas de comunidad (Rivera, 1983).

${ }^{7}$ La cifra es a diciembre del 2014 y no es estable. Existen aún peticiones pendientes de reparto así como, y por las recientes reformas, extinción de NA. Sólo de septiembre del 2013 a diciembre del 2014 han sido añadidos 70 Núcleos Agrarios. Por otro lado el repartimiento de suelo, y desde la Ley Agraria de 1992, ha sido disímbolo. Por ejemplo en el sureste de México, en Campeche, se ha generado un solo NA, mientras que en Chiapas, como caso emblemático, se han constituido cerca de $900 \mathrm{NA}$, lo que representa que de cada diez nuevos NA promulgados en el país, poco más de seis se han creado en dicho estado. A ello debe agregarse que el número de NA de una entidad no es proporcional a su extensión de suelo social. Por ejemplo Veracruz, siendo el estado con mayor número de NA con 3.725, el $40 \%$ es suelo social. En contraste en Morelos, el 75\% de su territorio es social y se distribuye en 231 NA.
} 
En esta repartición no se reservó suelo para el crecimiento de las ciudades de administración municipal (Duhau, 1991). Esta situación logra afectar no sólo a las principales capitales del país, sino también a las ciudades medias y poblaciones menores lo cual, aunque varía en cada caso, representa algo así como dos terceras partes de la tierra que colinda a dichos polígonos urbanos. Bajo lo anterior, el mayor crecimiento de las ciudades sería utilizando suelo ${ }^{8}$ de los NA, por lo que atendiendo a su régimen jurídico, inevitablemente, en algún sentido, sería extralegalmente (Hardoy y Satterhwaite, 1989). De esta manera, la reforma agraria si bien resolvió un problema, simultáneamente — sin tomar medidas para su mitigacióngeneró otro mayor, de ahí que para Hernández González (2004), el crecimiento irregular de la ciudad mexicana es un problema que tiene su origen, por lo menos, en la falta de previsión por parte del Estado nacional.

\section{El planeamiento sin territorio}

Con breves intervenciones reflexivas, serían los dos posicionamientos ${ }^{9}$ del urbanismo de Praxis los que dominarían el quehacer de la ciudad posrevolucionaria. Los intervencionistas, que estarían determinados por acciones desde lo privado con tendencia de Mercado y, los reglados o reformistas, usualmente enmarcados en una política de Estado, que se distinguirían por establecer constitucionalmente el zo$n^{10}{ }^{10}$, o zonificación, a finales de la década del setenta como modelo obligatorio y homogeneizante en el ordenamiento del crecimiento de las ciudades.

En la planificación y sus modelos, lejos de discutir su utilidad o vigencia, en el caso mexicano han convivido, de origen, las dos principales y opuestas tesis que la sustentan como ejercicio. En un extremo la liberal, que promueve a lo privado -o individual - y al mercado, y en otro la de Estado, que se caracteriza porque lo público o lo "dirigista" es lo dominante. Es la última tesis, y sus contradicciones ideológicas entre la libertad y la igualdad, la que imperó originalmente el debate

\footnotetext{
${ }^{8}$ Entre 1995 y el año 2000, y solo como un dato, el crecimiento urbano de las cuatro grandes zonas metropolitanas y las 116 ciudades medias del país, demandaron 150 mil hectáreas de suelo libre. De éstas, 105 mil fueron de la llamada propiedad social (SEDESOL, 2001).

${ }^{9}$ El urbanismo de Praxis está compuesto por intervencionistas y por reformistas. Junto a la actividad de los sociólogos de la ciudad, se conformarían las tres rutas de la urbanística: la intervencionista o de acción, la regulatoria o normativa y la del pensamiento o crítica (Baigorri, 2003).

${ }^{10}$ Con fundamentos de exclusión, de origen alemán y localizado desde finales del siglo XIX, el zoning o zonen (zonificación), según Mancuso (1980), se basa en el principio de la subdivisión de la ciudad asignando a cada una de dichas subdivisiones determinados parámetros relativos a la edificación. En general, y salvo casos de aplicación particulares, estos parámetros son tres: el uso, la densidad y la altura de las edificaciones.
} 
teórico. Auspiciado por la Carta de Punta del Este ${ }^{11}$, para la década del sesenta, el planeamiento como ejercicio había ya permeado a la América Latina (Lira, 2006). Antes de dicho acuerdo, sin embargo, el incipiente Estado mexicano observaba ejercicios tenues sobre planificación en donde el territorio se introducía como categoría.

Uno de los primeros antecedentes donde lo territorial es considerado en el planeamiento, refiere a la Ley sobre Planeación General de la República de 1930. En su redacción, es notable la visión de arquitecto urbanista de los autores manifestado en la jerga y el sesgo doctrinario de la urbanística en boga. Por ejemplo, en los considerandos, y en clara mención al aludido zonen, indicaba que para el progreso de las ciudades modernas se hacía necesario formular no un Plan sino un "Plano Nacional de México". Éste contendría, entre otros elementos:

1) la división del territorio nacional en zonas, clasificándolas de acuerdo con susdistintos caracteres, sus funciones propias y según los diferentes usos a que se destinen, $y$

2) la planeación y zonificación urbana y regional, y la formación de los Planos Reguladores del Distrito y Territorios Federales (art. 3).

Con esta Ley General se facilitaría para 1933 la definición del primer Plan Sexenal del país ${ }^{12}$ (Carrillo Barradas, 2002; Sánchez, 2008), además de la promulgación de la primera legislación urbana del México moderno: la Ley de Planificación y Zonificación del D.F. y territorios de Baja California ${ }^{13}$; en la cual se ponía en práctica, además del zonen, a un instrumento no vinculante que, discrecionalmente, se adoptaría en las principales ciudades del país durante casi medio siglo: los planos reguladores ${ }^{14}$.

La década del setenta marcaba un cambio global. Por un lado, y ante el agotamiento keynesiano, en el sistema económico mundial se consolidaba una nueva ortodoxia económica caracterizada por restringir el papel del Estado y privilegiar al individualismo a partir de la libertad de mercado: la utopía neoliberal (Harvey, 2007). Paralelamente, el urbanismo como disciplina cartesiana que buscaba "cientí-

\footnotetext{
${ }^{11}$ En un principio, el acuerdo de Punta del Este trae consigo un par de eventos contradictorios. En un lado, posibilita que los países planifiquen sin acusarlos de comunistas, pero en otro, la realización de los documentos de planificación no funcionaron como un medio decisorio, sino como un fin para conseguir recursos internacionales a fondo perdido y para aumentar la burocracia local (Moreno Valle, 1979; Lira, 2006).

${ }^{12}$ Aunque en realidad se trataba de un instrumento de promoción política de la campaña de Lázaro Cárdenas a la presidencia del país que, posteriormente, se convertiría en el primer Plan Sexenal 1934-1940 (García Moctezuma, 2010).

${ }^{13}$ Además del Reglamento de Arquitectura del Distrito Federal.

${ }^{14}$ Para un rápido acercamiento a los antecedentes legislativos territoriales del país, se sugiere la obra de Ugalde (2010) y la de Sánchez (2008), entre otros.
} 
ficamente" la ciudad racional y funcional a partir de premisas y propuestas homogeneizadoras, inequívocas, unívocas, unidireccionales y universales, enfrentaría un descrédito por su incapacidad ante la complejidad urbana.

En ese contexto, y a pesar de ello, el Estado nacional decide implantar ${ }^{15}$ una "vanguardista" ideología derivada del pensamiento universalista del Movimiento Moderno de las Ciudades. El advenimiento de esta ideología asentista, que se instalaría en el lenguaje de su vigente urbanística, se posibilitaría desde la aparición de la denominada "tecnocratización ${ }^{16 "}$ de la administración pública mexicana, particularmente con la llegada al poder del ex Secretario de la Presidencia, Luis Echeverría Álvarez (Hiernaux, 1992; Ai Camp, 1983). Su implementación, empero, se facilitaría también a partir de otras coyunturas tales como:

a) La conformación por parte de la Secretaria de la Presidencia y de un grupo de expertos de la ONU, del Proyecto de Desarrollo Regional y Urbano en 1972.

b) La relevancia y sobredimensión que la urbanización ejidal había adquirido como botín político. Lo que generó presión y críticas nacionales e internacionales por la actuación del gobierno con prácticas heredadas desde el cardenismo como el corporativismo y la simulación (Azuela de la Cueva, 1989).

c) El compromiso por parte del Estado mexicano, por acuerdos internacionales como el de Hábitat I celebrado en 1976 en Vancouver, de atender el fenómeno urbano.

d) La crisis del modelo de dominio corporativo (Meza Ramos, 1987).

e) El surgimiento de organizaciones de colonos independientes al partido oficial, genéricamente denominados Movimiento Urbano Popular (MUP) ${ }^{17}$.

Así, desde el imaginario de régimen, el discurso oficialista intenta convencer de que debería sustituirse el - hasta ese momento- vigente modelo de desarrollo basado en las Regiones Homogéneas por el —ahora- basado en los Asentamien-

\footnotetext{
${ }^{15}$ No se olvide que, tal como se ha planteado, sólo se institucionalizaba un modelo que ya desde la década del treinta se utilizaba en diversas ciudades del país.

${ }^{16}$ Para un mejor entendimiento de la coyuntura, implicaciones y definición, se sugiere el texto de Roderic Ai Camp (1983).

${ }^{17}$ El MUP en México, se remonta a 1915 y comprende a grandes contingentes de la población urbana (aunque minoritarios en relación al conjunto) que han desarrollado luchas independientes por el acceso al suelo, la vivienda y los servicios públicos [entre otros] (Moctezuma, 1985-1986). Paralelamente, y como reducto de las protestas de 1966, los movimientos ciudadanos de reivindicaciones urbanas, en la segunda mitad de la década del 70, también habían adquirido una importancia sin precedentes en otros países, tal es el caso Español, particularmente en la urbanización del extrarradio de la ciudad de Madrid (Roch, 2002).
} 
tos ${ }^{18}$. Las ciudades, como segundo punto de quiebre, se erigirían como los nuevos enclaves de modernidad y progreso, por lo que el problema de la irregularidad y la precariedad, después de desdeñarse y tratarse como un asunto secundario por varias décadas, debería asumirse como una política de Estado (Azuela de la Cueva, 1989; Duhau, 1991).

En este nuevo esquema asentista se destacan tres acciones:

1) durante el periodo echeverrista, la creación en 1971 del Programa para la Promoción de Conjuntos, Parques, Ciudades Industriales y Centros Comerciales;

2) en 1976, la promulgación de la Ley General de Asentamientos Humanos (LGAH), y

3) al inicio de régimen de López Portillo, la creación de una Secretaría de Estado exclusiva para las ciudades: la Secretaria de Asentamientos humanos y Obras Públicas (SAHOP).

Para la primera acción, bajo el discurso de reducir las desigualdades sociales del país, se crea el "Fideicomiso de Conjuntos, Parques, Ciudades Industriales y Centros Comerciales" (FIDEIN). Se pretendía con ello reducir el desequilibro provocado por las tres regiones industriales ubicadas en las tres zonas metropolitanas existentes (Garza Villareal, 1992a). En la segunda, con la LGAH, se buscaba:

a) homogeneizar y coordinar las legislaciones de los tres niveles de gobierno;

b) integrar la dimensión espacial a las políticas regionales;

c) institucionalizar el planeamiento urbano, e,

d) instrumentar las políticas de desarrollo urbano de los asentamientos humanos (Ramírez Saiz, 1992).

Para la tercera acción, la SAHOP:

Constituiría en el eje central del sistema de planificación urbana nacional, pues se encargaría de formular y coordinar la política general sobre asentamientos humanos a nivel interurbano (ordenamiento del territorio) e intraurbano (ordenamiento de la estructura urbana) (Garza Villareal, 1992b: 30).

\footnotetext{
${ }^{18}$ Lejos de discutir lo rural o lo urbano, se asimila el concepto de "asentamiento" para referirse indistintamente a cualquier población. Aunque según Azuela de la Cueva (2014), la apropiación del término obedece más bien a la "prueba de su liderazgo" del Estado mexicano en su participación y compromisos en la Conferencia de las Naciones Unidas sobre Asentamientos Humanos (Hábitat I).
} 
Para ello publicó un sinnúmero de documentos teórico-prácticos ${ }^{19}$ tales como manuales, guías, glosarios, normas, modelos y métodos para el desarrollo y puesta en práctica de planos y planes urbanos de cualquier tipo y nivel ${ }^{20}$. Además, y de mayor relevancia, el Estado introdujo en 1976 y 1977 modificaciones y terminología a la Constitución Política del país que desembocaría en la promulgación de la citada $\mathrm{LGAH}^{21}$ (Gráfico 2).

De esta forma, y con carácter de obligatoriedad, se pretendía legitimar, homogenizar y racionalizar los criterios y fundamentos jurídicos de las ciudades y localidades del país. Concretamente, con el control y regulación de su crecimiento a través de la realización y promulgación de instrumentos técnico-científico-jurídicos que, y en clara imitación a los planes reguladores de inicios del siglo XX, se denominarían "Planes de Desarrollo Urbano de Centros de Población" (PDUC). Los que, y es quizá la parte central, de acuerdo al artículo 115, serían una facultad exclusiva del gobierno municipal:

\section{Artículo 115.}

$[\ldots]$

V. Los Municipios, en los términos de las leyes federales y Estatales relativas, estarán facultados para:

$[\ldots]$

a) Formular, aprobar y administrar la zonificación y planes de desarrollo urbano municipal;

b) Participar en la creación y administración de sus reservas territoriales;

[...]

d) Autorizar, controlar y vigilar la utilización del suelo, en el ámbito de su competencia, en sus jurisdicciones territoriales.

\footnotetext{
${ }^{19}$ La Secretaria de Asentamientos Humanos y Obras Públicas (SAHOP), antecedente de la vigente SEDESOL y la actual SEDATU, publicó entre finales de la década del 70 y durante la del 80 , a través de la Dirección General de planeación territorial de Asentamientos Humanos, una serie de guías o manuales para la elaboración de dichos documentos. Particularmente los Manuales para elaboración de Planes (en el caso de poblaciones urbanas) y los Esquemas (en el caso de poblaciones rurales) de Desarrollo Urbano, representaron un hito técnico metodológico, al menos en la elaboración de dichos documentos. No obstante, según Gutiérrez (2014), en realidad la SAHOP lo que hizo fue "construir", desde un modelo de Planeación Racional Desarrollista, un método particular de etapas sucesivas con miras a elaborar un Plan en donde el zoning funcionaba como método, modelo y técnica. Es decir, su propuesta solo institucionaliza (o centraliza) y pretende homogenizar - además de volverlos vinculantes- lo que en la práctica ya existía en el último medio siglo.

${ }^{20}$ Es de destacarse que estos modelos, guías y manuales para la construcción de un Plan o Esquema de Desarrollo Urbano, referían exclusivamente a ciudades ganadoras, es decir, aquellas que ininterrumpidamente aumentaban su Área urbana $(\mathrm{Au})$ a la vez que su población.

${ }^{21}$ Ambas acciones con una clara fundamentación en las propuestas de Movimiento Moderno de las Ciudades, particularmente con la obligatoriedad del zoning como metaherramienta para generar — según la propia Ley General- "el desarrollo urbano de los centros de población, [tendiente] a mejorar el nivel y calidad de vida de la población urbana y rural (art. 3).
} 
Gráfico 2. Línea de tiempo y síntesis sobre instituciones, marcos normativos e instrumentos del planeamiento urbano territorial en México

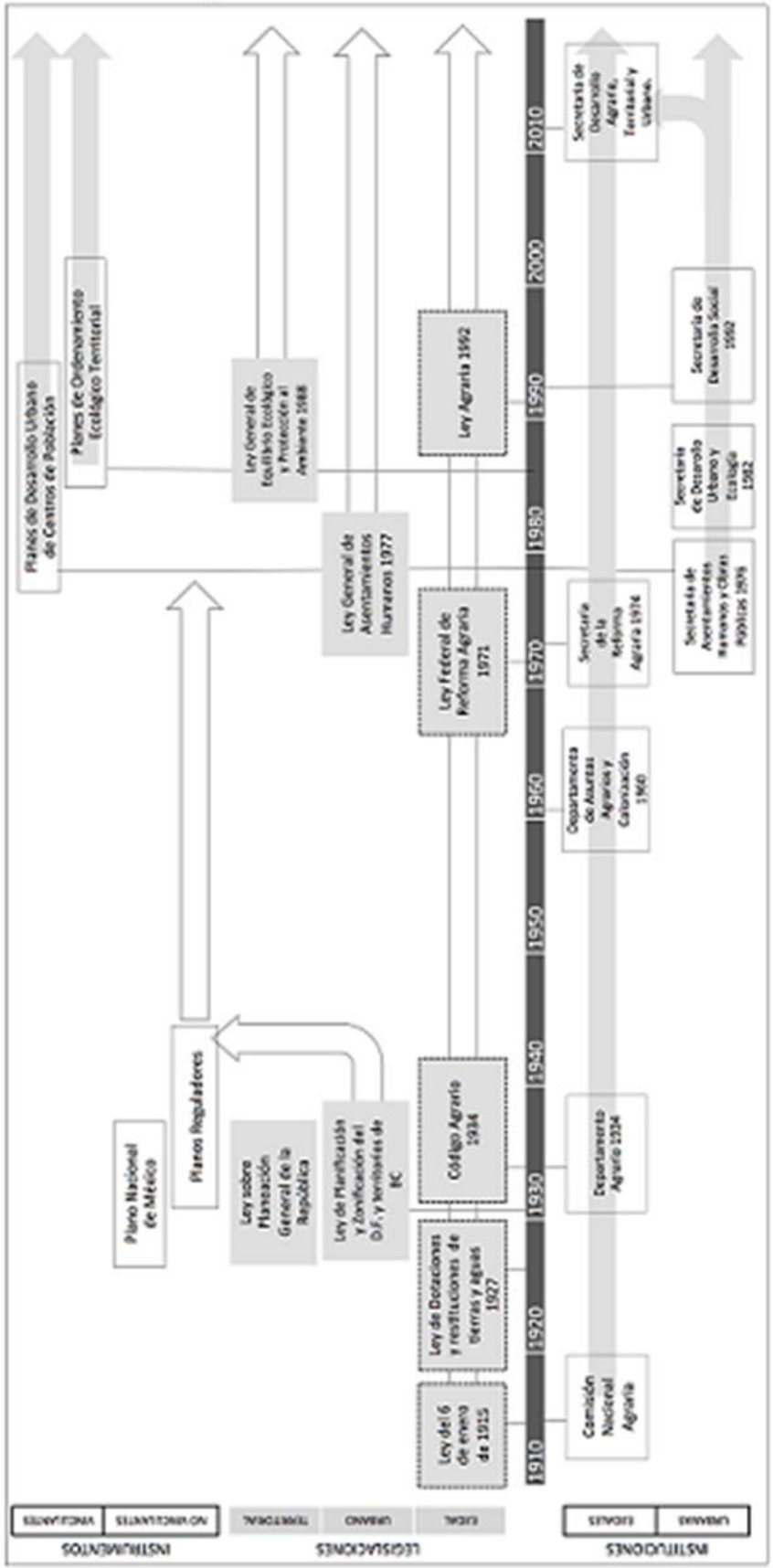

Fuente: elaboración propia. 
Así, sobre todo durante el sexenio lópezportillista, la gran producción documental de normas, leyes, reglamentos, ordenanzas jurídico urbanas y de documentos de control urbano tales como planes y planos urbanísticos, consolidan una pretendida política de Estado intervencionista que, a la postre, desembocaría en una superestructura jurídico urbana compuesta de leyes, reglamentos, planes y programas (vinculantes o no) en sus tres niveles, tendientes a normalizar y regular el crecimiento y funcionamiento de sus ciudades. Dicho de otra forma, que con la institucionalización del modelo urbanístico mexicano, se buscaba integrar tanto la tradición intervencionista y de control, como la tradición regulatoria, y los planes y planos urbanos de cualquier nivel funcionarían como los inmejorables instrumentos vinculantes y vinculatorios entre ambos posicionamientos. No obstante, y a pesar de esta generación de instrumentos, políticas y la gran burocracia especializada, la discusión entre municipalismo y agrarismo vuelve a esquivarse.

En ello, hay dos razonamientos que merecen destacarse: el carácter timorato de la reforma urbana y su politización. Ramírez Saiz (1992) achaca a la crítica oligárquica $^{22}$ el repliegue de las atribuciones originales del municipio. Estas prerrogativas, dice el autor, en un principio otorgaban a las autoridades locales suficientes "facultades y atribuciones" administrativas y legales para ordenar y administrar los usos del suelo de su jurisdicción, lo que incluía el suelo de los NA. De la misma manera, Azuela de la Cueva (1992) concluye que las atribuciones territoriales del municipio fueron escamoteadas, precisamente, por razones de poder político, particularmente el partidista, de tal forma que el tema de la propiedad ejidal continuaría siendo el principal obstáculo jurídico para la planeación urbana y que, lejos de incluirse o discutirse, permaneció soslayándose.

En todo caso, si en la reforma agraria el municipio cedió, además de autoridad, la propiedad de su territorio, la posterior reforma al artículo 115 de 1983, le procuraba compensar - al menos en papel - sus competencias para normar, controlar y regular el crecimiento de sus ciudades y el territorio sin importar la propiedad. A partir de este momento, la teoría legislativa dictaría que el municipio sería el encargado de la elaboración, aprobación y administración de los instrumentos de política urbana y territorial. Aunque, y con el antecedente de más de cinco décadas de práctica consuetudinaria, el orden urbano continúo supeditado al agrario. El daño ya estaba hecho.

Al cabo, la Secretaria de las ciudades duró lo que dura un periodo político administrativo. La década del ochenta se establece como la década del tercer quiebre en el planeamiento. Simultáneamente a la referida reforma al 115 de 1983, se promul-

\footnotetext{
${ }^{22}$ Al igual que en la reforma agraria, en que se repartió suelo principalmente de la propiedad de las Haciendas, se temía una reforma urbana que repartiera, para uso urbano, el suelo vacante de las ciudades (Garza Villareal, 1992a).
} 
ga la Ley de Planeación que, en la praxis, sustituyó a la planeación urbana por la económica. De esta forma los Planes Económicos supeditaron a los urbanos a los que la tecnocracia de régimen denominaban como "representaciones cartográficas voluntaristas" (Azuela de la Cueva, 2014: 58), por lo que los instrumentos de Desarrollo Urbano (DU) pasaron a un plano simbólico y rutinario. Por otro lado, y acorde con el lenguaje global políticamente correcto, en 1988 nace la Ley General de Equilibrio Ecológico y Protección al Ambiente misma que, y más allá del discurso ambientalista, buscaba ordenar - ahora - los usos del suelo rural y el no antropizado. Así, en el papel, el territorio y las aguas del país se organizaban a partir de dos tipos de instrumentos. Por un lado, y a manera de "ventanas", los devaluados instrumentos de DU para las ciudades, y por otro, los "prestigiosos" instrumentos de Ordenamiento Ecológico Territorial (OET) para el resto del suelo y aguas nacionales (Gráfico 2). Con ello, y a pesar de que el conjunto instrumental y jurídico que afectaba al territorio se complejizaba aún más, la discusión sobre el suelo y la autoridad ejidal vuelve a ignorarse.

Cuadro 1. Autoridades e instrumentos vinculantes del territorio

\begin{tabular}{|c|c|c|c|c|c|c|c|c|c|}
\hline & \multicolumn{3}{|c|}{ AGRARIO } & \multicolumn{3}{|c|}{ URBANO } & \multicolumn{3}{|c|}{ ECOLÓGICO } \\
\hline & $\begin{array}{c}\text { Leyes } y \\
\text { Reglamentos }\end{array}$ & Instrumentos & Autoridades & $\begin{array}{c}\text { Leyes y } \\
\text { Reglamentos }\end{array}$ & Instrumentos & Autoridades & $\begin{array}{c}\text { Leyes y } \\
\text { Reglamentos }\end{array}$ & Instrumentos & Autoridades \\
\hline Nacionales & \begin{tabular}{|l} 
Ley Agraria \\
Ley Federal \\
de la Ref. Agraria
\end{tabular} & & \begin{tabular}{|l} 
Presidente \\
SEDATU \\
PA \\
\end{tabular} & LGAH & PNDU & SEDESOL & LGEEPA & \begin{tabular}{|l|} 
POEGT \\
POERT \\
POE Marinos \\
\end{tabular} & $\begin{array}{l}\text { SEMARNAT } \\
\text { INE } \\
\text { PROFEPA } \\
\end{array}$ \\
\hline Estatales & & & & LEAHDUEN & $\begin{array}{l}\text { PEDU } \\
\text { P de Conurb } \\
\text { P Reg DU }\end{array}$ & \begin{tabular}{|l|} 
Gobernador \\
SOSP \\
IPROVINAY
\end{tabular} & LEEEPAEN & $\begin{array}{l}\text { POEE } \\
\text { POER }\end{array}$ & SEMANAY \\
\hline Municipales & & & & \begin{tabular}{|l|} 
Reglamentos \\
Zonificación \\
Construcción
\end{tabular} & \begin{tabular}{|l} 
PMDU \\
PDUCP \\
PP \\
\end{tabular} & $\begin{array}{l}\text { Org. Mpales } \\
\text { de urbanismo } \\
\text { y vivienda }\end{array}$ & & $\begin{array}{l}\text { POEM } \\
\text { POEL }\end{array}$ & Org. Mpales \\
\hline Otros & & \begin{tabular}{|l} 
Resoluciones \\
Presidenciales \\
de Dotación de \\
Tierras \\
\end{tabular} & $\begin{array}{l}\text { Asamblea } \\
\text { Comisariado }\end{array}$ & & & CAC & & & \\
\hline
\end{tabular}

Fuente: Elaboración propia (las siglas estatales refieren a Nayarit).

A partir de esta década, a la lógica del Mercado y a la lógica Agraria —en las cotidianas prácticas territoriales - se sumaría la lógica de los Ordenamientos Territoriales, tanto urbanos como ambientales (Cuadro 1). Por lo que desde entonces, puede ser usual que en un mismo metro cuadrado de suelo de un NA (Ejidal o Comunal) confluyan, además las reglas del mercado y los "Usos de Costumbres", los tres sistemas de leyes (agrario, urbano y ambiental), los tres instrumentos de ordenación (agrario ${ }^{23}$, urbano y territorial) y, también, los diversos tipos de orga-

${ }^{23}$ Las Resoluciones Presidenciales de Dotación de Tierras a los Poblados o NA Ejidales o Comunales especifican, entre otros datos, los usos del suelo de cada uno de los polígonos que han de comprender tal NA. 
nismos y autoridades, en cualquiera de sus tres niveles de gobierno. $\mathrm{Y}$ en esto último, aunque el marco jurídico diga lo contrario, luego de alrededor de ocho décadas de prácticas consuetudinarias, tradicionalmente en el suelo de los NA se reconoce como autoridad a las Asambleas Agrarias, complejizando aún más el fenómeno territorial en México.

\section{Las prácticas sustitutas}

Portilla (1984: 121) plantea que algunas formas y relaciones comunitarias - como las agrarias- ayudan a entender "ciertos rasgos del carácter nacional"; son provocadoras de identidad. En el imaginario nacional, el binomio suelo y comunidad consolidaría una ligazón a la cultura nacional si, por añadido, es de naturaleza indígena. El suelo comunal indígena, constituiría en consecuencia, un garante nacionalista, por lo que su afectación, supondría una afectación identitaria. Contradictoriamente - y como presagio- el histórico suelo comunal indígena, entre otros atributos, no era apto para su venta o alquiler. Pese a ello, bajo ciertos auspicios ${ }^{24}$, desde finales del siglo XVI y hasta bien entrado el siglo XIX, frecuentemente era arrendado y vendido a terceros aún en contra $-\mathrm{y}$ a veces en connivencia- de idiosincrasias colectivas, ordenanzas y del propio Cabildo (Gibson, 1967). Así que a estos elementos identitarios, se le agregaría el del vacío de autoridad y el del tráfico.

De manera que, desde siempre, la pugna por el suelo ha llevado simultáneamente un elemento utilitario. Una búsqueda de capitalizar una ganancia. Cualquier tipo de ganancia. Consiguientemente, si bien la lucha armada fue - como se ha dicho-, sobre todo una lucha de ideales agraristas, el sentido comunitario e indigenista permeó en la institucionalización y operación del ejido, pero también, y con sus propios auspicios, la búsqueda de esta capitalización de beneficios. Aunque para conseguirlo, ahora, hubieron de surgir diversos mecanismos -y consecuenciasde forma inmediata a la dotación de suelo de los NA con una particular intensificación en aquellos que colindaban a las ciudades.

Gordillo (1999) califica a los NA como un "instrumento de poder político". Los coloca de facto en una condición de subalternidad. Del mismo modo, tanto Durand (1983) como Warman (1980) establecen que las clases campesinas han negociado su suelo en condiciones asimétricas y verticales. Para lograrlo, y buscando nivelar esta negociación, han tenido que, según Fromm y Maccoby (1992), modificar su

\footnotetext{
${ }^{24}$ Gibson (1967: 282) menciona como tres las principales formas para adquirir suelo durante la colonia: la compra-venta, la encomienda y, el tercero de ellos, "la recepción directa de una Merced". Esta última, en realidad, suponía la legalización de las dos anteriores.
} 
personalidad de campesino a empresario. Esta modificación, no obstante, ha respondido más a situaciones de oportunidad bajo el principio del menor esfuerzo y mayor ganancia; es decir, de agentes pasivos y perdedores, se convierten en protagónicos.

Esta transformación de personalidad, empero, es diferenciada. Sin ser concluyentes, de manera general depende, por un lado, de las condiciones físicas y la ubicación geográfica del NA tales como su cercanía con una ciudad primada o su "atractividad" territorial ${ }^{25}$; esto es, por el valor de cambio del suelo. Pero por otro, a las condiciones culturales y generacionales del grupo en las que se incluyen temas como la memoria colectiva y el arraigo; o sea, sí es Ejido o es Comunidad, o si sus integrantes son de primera o subsecuente generación. Independientemente de ello, en cualquiera de estos comportamientos diferenciados, en esta búsqueda de capitalizar beneficios, se ha tenido que recurrir a la complicidad, patrocinio o, por lo menos, velada o evidente tolerancia de cualquiera de los grupos de poder que inciden en este territorio, por lo que las modificaciones atañen también a las autoridades $\mathrm{y}$, en menor escala, a la propia sociedad.

En 1953, bajo otro contexto y premisas, Redfield aseguraba que la ciudad mexicana se hizo posible por el trabajo de sus campesinos (Wolf, 1985). Esta afirmación no puede ser más actual. Sólo que ya no refiere a la excedencia de mano de obra y el producto de su suelo, sino al suelo mismo - y no precisamente en excedenciacon sus propias formas y entidades de legitimación. Su posición, sus condiciones, y su autogobierno - como se ha dicho-, posibilita reconocer a los NA con un protagonismo emergente en el quehacer de su ciudad y de la ciudad metrópoli o receptora, convirtiéndolos, a su vez, en causa y efecto; en otras palabras, en agentes productores y consumidores del control y de la ciudad misma.

En este control, directo o no, sus decisiones e históricas actividades de urbanización han llegado a suplir las competencias propias de las autoridades municipales y urbanísticas. La regularización del territorio ejidal, expedir documentos supletorios de propiedad, determinar los usos y destinos del suelo, facilitar sus cambios de usos, controlar las subdivisiones, fusiones o sesiones del suelo o modificar los límites y reservas de crecimiento urbano son ya parte de su cotidiana actividad "administrativa", lo que incluye, claro está, sus consecuencias, como la generación y apropiación de plusvalías, la inutilidad de la planificación territorial oficialista o la subordinación del municipio.

\footnotetext{
${ }^{25}$ De manera general se distinguen cuatro comportamientos: 1) aquellos que ya forman parte de un Centro de Población; 2) los que están en el hinterland urbano de las ciudades y que reciben o están próximos a recibir una demanda de su suelo; 3) con valores paisajísticos o atractivos que los hacen vulnerables a la búsqueda de su suelo, y 4) independientes, que no están en ninguno de los supuestos anteriores.
} 
Por esta libertad e independencia, a menos que desaparezcan o se desincorporen totalmente, los NA seguirán siendo los principales suministradores y administradores de suelo urbanizable, debido a que:

1) Al vender, el ejidatario infringe normas políticamente distintas a las de los fraccionadores privados, y aunque el delito lo comete quien vende y no quien compra, en los "usos y costumbres" esto no es imputable a los ejidatarios.

2) El que compra suelo ejidal disfruta de una relativa seguridad en la posesión, sabe que son muy raros, por no decir ninguno, los desalojos en este tipo de suelo.

3) La expropiación del suelo ejidal, como medida de regularización de su tenencia, implica necesariamente una indemnización por el acto, lo que conlleva un doble ingreso económico para el ejidatario (cuando vende y cuando se le expropia). Situación generalmente buscada.

4) Si bien el acceso a este tipo de suelo representa a la larga un alto coste económico, también ha representado la alternativa adecuada no solo para el habitante - debido a que el desembolso es gradual y limitado-, sino también para el Estado, para el cual, la urbanización de los Ejidos, al ser proveedores sustitutivos de suelo, ha resultado un providencial elemento de aminoramiento de distensión social.

5) En estos procesos paralelos de crear ciudad, las mutuas ganancias de plusvalía y de legitimación interdependiente entre los grupos involucrados, representa también uno de los mayores atractivos que impide su desaparición.

\section{A manera de conclusiones}

En la búsqueda de reducir las incertidumbres sobre la relaciones institucionales, y considerando lo planteado a lo largo del texto, cuatro elementos deben destacarse. Primero. En su trato con las comunidades indígenas -y particularmente con las campesinas - tradicionalmente, y sobre todo desde el modernismo posrevolucionario temprano, el Estado mexicano ha mantenido una deferencia sistemática. Segundo. El municipio, no obstante y proclamarlo constitucionalmente como la institución base de la organización del gobierno de México, históricamente se ha caracterizado por tener un trato de subordinación con otros poderes. Así que a la falta de previsión, a lo timorato y el carácter de politización del Estado en su toma de decisiones sobre el territorio - específicamente el referido para el crecimiento de las ciudades-, ante este par de instituciones debe resaltarse, además del desdén a los municipios, su continuado posicionamiento preferencial, traducido en franco tutelaje, hacia las comunidades agrícolas. 
Por ello no es extraño, entonces, que durante el reparto agrario, artificiosamente surgieran campesinos. Los NA Ejidales, a diferencia de los Comunales, de manera prolongada se constituyeron por ejidatarios que, en su origen, tenían una variedad de oficios $-\mathrm{u}$ ocupaciones-, como guardias, policías, carpinteros, peluqueros, amas de casa o burócratas. De pronto se tornó prestigioso y conveniente ser campesino. Sin embargo, y más allá de lo anecdótico de este evento, esta mezcla de impunidad con oportunismo marcó el devenir de la relación entre el Estado mexicano, el municipio y los NA, siendo estos últimos los que consolidarían una primacía que, ante la connivencia del primero, fortalecería su antagonismo con los segundos, especialmente en temas que tengan que ver con el suelo del tipo social y destinado para los asentamientos humanos.

Así es, tal como se ha descrito, en los temas sobre el suelo, los NA suelen comportarse por encima de los gobiernos estatales, llegando a advertirse, en algunos casos, relaciones horizontales con los otros niveles de gobierno pero difícilmente en subordinación. Los NA, y debe recordarse, pueden modificar y decidir usos y reservas urbanas del suelo o la aceptación de nuevos avecindados y ejidatarios, pero bajo ninguna circunstancia en sentido inverso; es decir, los Cabildos no podrían influir directamente en el territorio o los integrantes de los NA, y menos sí estos son rurales o están fuera de la demanda del mercado. Así que si bien la colisión entre ambos sistemas territoriales no es homogénea, si es convenientemente desapercibida, reservando la intervención del nivel federal solo bajo circunstancias específicas.

Efectivamente, en México las decisiones se toman toda vez que no hay tiempo para postergarlas. Éstas —una vez implementadas-, no obstante, no se desposeen de una intencionalidad en la búsqueda de, como se ha planteado, cualquier tipo de beneficio. Así, las modificaciones a las leyes agrarias, el surgimiento de la legislación y burocracia especializada en las ciudades, son parte de la improvisación sexenal que debe cubrirse con discursos llenos de disimulo y sólo caracterizable desde un tiempo-espacio de clasificación al estilo de Wallerstein (1998). Este timing $-\mathrm{y}$ sus efectos-, empero, producen externalidades que, a su vez, son generadoras de nuevos ciclos de improvisación y picardía desde lo político y desde la política.

Además de su carácter identitario, Portilla (1984) defiende el sentido utilitario de la comunidad. Él propone que sólo desde este asociacionismo es -y ha sidoposible sobrellevar la inestabilidad del exterior. Por lo cual, y aceptando que la noción patria-territorio fue un concepto ajeno hasta bien entrada la independencia (Benítez et al., 2014), sería el asociacionismo, en este caso ejidal, un nivel de identidad-gobierno que, entre otras cosas, definiría y soportaría las actividades y las cambiantes políticas territoriales mexicanas. En consecuencia, cuando hablamos de ejidos, a diferencia de las Comunidades Agrarias - de las que en todo caso se podría hablar de comunalidad-, aunque no necesariamente se describe en el sentido antagónico de sociedad planteado por los culturalistas, sí incluye sus rasgos y sus prácticas. 
Así que en la construcción del empoderamiento de los NA, al tutelaje debe agregarse, como un tercer elemento, el asociacionismo comunitario. La asociación en comunidad, y siguiendo a Portilla (1984), además de entenderse como una necesidad con raigambre histórico y cultural, posibilita las relaciones al nulificar la otredad trastocándola por el nosotros con una atenuante, y es que también posibilita la adaptación del grupo ante cualquier situación planteada por los muchos méxicos en que estas numerosas y variadas comunidades perviven. Pero no debe confundirse. Esto no ha sido por una prerrogativa del Estado mexicano empecinado en conservar discursivamente el sentido comunitario bajo el mito del romántico calpulli precolombino. No, desde su origen, constituyó la respuesta que representaba, como se ha dicho, la mayor ganancia. En primera instancia, con los iniciales actos revolucionarios que pretendían "devolver" el suelo a las comunidades indígenas a través de Restitución, en realidad se instauró una búsqueda de legitimación política del naciente Estado para luego, con Cárdenas, transitar a la búsqueda de capital político corporativo y terminar en la lógica del mercado financiero y su búsqueda de plusvalías; aunque en la actualidad, y luego de prácticas consuetudinarias, no se tenga bien claro las demarcaciones de cada una de ellas.

De modo que la flecha del tiempo, como cuarto elemento, debe destacarse. Si las Asambleas Ejidales han sido el mejor recurso de estabilidad ante una vacilante geopolítica nacional —además de constituirse como el espacio que ha otorgado arraigo e identidad a sus integrantes-, no debe olvidarse que su fuerza radica en la relativa independencia en que han desarrollado sus decisiones -y por el tipo de decisiones que toman - , pero, sobre todo, que dicha canonjía ha trascendido - y se ha practicado- por más de tres generaciones. El ejido, desde las Asambleas Ejidales, y luego de ocho décadas de actividad protoautónoma con un continuado ejercicio del derecho indiano criollo, ha sido capaz de trazar una ruta y una estética - con características de irreversibilidad - sólo identificable con un cuarto nivel de poder. Por lo que, y como corolario, si existe una institución posrevolucionaria que refleje y haya ejercido un real, continuo y continuado poder político y administrativo territorial en el México contemporáneo, han sido los NA en su modalidad de ejido. En consecuencia, y desde la lógica y emergencia de este cuarto nivel de poder, serán éstos y sus prácticas los que conservarán, definirán y trascenderán el peculiar posmodernismo nacional referido, al menos, en su relación con los otros tres niveles de gobierno en temas que tengan que ver con el planeamiento territorial, esencialmente el urbano, lo que incluiría, invariablemente, a la urbanística y a la urbanización de las ciudades mexicanas.

\section{Bibliografía}

Ai Camp, Roderic (1983) "El tecnócrata en México". Revista Mexicana de Sociología, vol. 45, núm. 2, 579-599. [URL: 
$<$ http://www.jstor.org/discover/10.2307/3540261?uid=2478037167\&uid=2134\& uid $=2$ \&uid $=70$ \&uid $=3 \&$ uid $=2478037157 \&$ uid $=60$ \&purchasetype $=$ none $\&$ access $T y p e=$ none $\&$ sid $=21104180882217 \&$ showMyJstorPss $=$ false $\&$ seq $=3 \&$ showAccess=false $>$. Consultado el 12 de Abril de 2015].

Azuela de la Cueva, Antonio (1989) "La institucionalización de las colonias populares y la política urbana en la ciudad de México (1940-1946)". Sociológica, vol. 9, núm. 4, s. p. [URL: <http://www.revistasociologica.com.mx/pdf/0906.pdf>. Consultado el 16 de noviembre de 2015].

Azuela de la Cueva, Antonio (1992) "El significado jurídico de la planeación urbana en México", en G. Garza (coord.) Una década de planeación urbanoregional en México, 1978-1988. México: El Colegio de México, 55-77.

Azuela de la Cueva, Antonio (1999) La ciudad, la propiedad privada y el derecho. México: El Colegio de México.

Azuela de la Cueva, Antonio (2014) "El ordenamiento territorial en la legislación mexicana", en M. T. Sánchez Salazar et al. (coords.) La política de ordenamiento territorial en México: de la teoría a la práctica. México: UNAM, 47-77.

Baigorri, A. (2003) "Urbanismo y urbanistas en la urbe global". Conferencia impartida en el Seminario: Urbanismo: ¿cambios o permanencias?, Escuela interdisciplinar de postgrados, Facultad de Artes, Universidad Nacional de Colombia, Bogotá.

[URL: $<$ http://facartes.unal.edu.co/portal/publicaciones/urbanismos/urbanismos1/3Urba nismoyurbanistasenlaurbeglobal.pdf $>$. Consultado el 12 de Enero de 2015].

Baitenmann, Helga (2001) "Las paradojas de las conquistas revolucionarias: municipio y reforma agraria en el México contemporáneo". Gestión y Política Pública, vol. $\mathrm{X}, \mathrm{núm.} \mathrm{1,} \mathrm{103-123.} \mathrm{[URL:}$ $<\mathrm{http} / /$ www.redalyc.org/articulo.oa?id=13310104.pdf $>$. Consultado el 31 de Octubre de 2014].

Benítez, Gabriela et al. (2014) "Legados conceptuales en las imágenes de la memoria histórica", en R. Monroy et al. (coords.) Paisaje y Memoria histórica en el urbanismo y la arquitectura de los pueblos de México. Cuernavaca: UAEM, 4570.

Carrillo Barradas, José Luis (2002) Teoría y práctica en la configuración de la megalópolis. Influencias de las escuelas norteamericana y francesa de arquitectura, urbanismo y economía en el caso de la ciudad de México. Tesis Doctoral inédita en la Universidad Politécnica de Madrid.

Contreras Valdez, José M. (2001) Reparto de tierras en Nayarit, 1916-1940: un proceso de ruptura. México: INEHRM.

Duhau, Emilio (1991) "Tierras ejidales y políticas de suelo en la ciudad de México". Medio ambiente y urbanización, vol. 9, núm. 34, 43-59.

Durand, Jorge (1983) La ciudad invade al ejido, proletarización urbanización y lucha política en el cerro del Judío, D. F. México: SEP, La Casa Chata.

Eckstein, Salomón (1966) El ejido colectivo en México. México: F.C.E. 
Fromm, Erich, y Maccoby, Michael (1992) Sociopsicoanálisis del campesino mexicano. México: FCE.

García Moctezuma, Francisco (2010) "La planeación del desarrollo regional en México (1900-2006)". Investigaciones Geográficas, Boletín del Instituto de Geografía, núm. 71, 102-121. [URL: $<$ www.scielo.org.mx_pdf_igeo_n71_n71a9.pdf >. Consultado el 20 de Diciembre de 2014].

Garza Villareal, Gustavo (1992a) Desconcentración, tecnología y localización industrial en México. México: El Colegio de México.

Garza Villareal, Gustavo (comp.) (1992b) Una década de planeación urbanoregional en México, 1978-1988. México: El Colegio de México.

Gibson, Charles (1967) Los aztecas bajo el dominio español (1519-1810). México: Siglo XXI.

Gordillo, Gustavo et al. (1999) La segunda reforma agraria de México: respuestas de familias y comunidades, 1990-1994. México: FCE.

Gutiérrez, J. (2014) "La obsolescencia del modelo de atención territorial: contribuciones desde la teoría de planificación", en M. T. Sánchez Salazar et al. (coords.) La política de ordenamiento territorial en México: de la teoría a la práctica. México: UNAM, 501-520.

Hale, Charles A. (1997) "Los mitos políticos de la nación mexicana: el liberalismo y la revolución”. Historia Mexicana, vol. 46, núm. 4, 821-837.

Hardoy, Jorge Enrique, y Satterhwaite, David (1989) "En las ciudades del tercer mundo la ley no es pareja para todos". Ciudad y Territorio, núm. 81-82,157-166.

Hernández González, Agustín (2004) "Los Asentamientos humanos irregulares en zonas rurales conurbadas: un problema de justicia social". Revista de los Tribunales Agrarios, vol. I (2 $2^{\mathrm{a}}$ época), núm. 32, 5-24.

Harvey, David (2007) Breve historia del neoliberalismo. Madrid: Akal.

Hiernaux, Daniel (1992) "La planeación de la ciudad de México: logros y contradicciones", en G. Garza Villareal (comp.) Una década de planeación urbanoregional en México, 1978-1988. México: El Colegio de México, 233-252.

Knowlton, R. (1978) "La individualización de la propiedad corporativa civil en el siglo XIX - Notas sobre Jalisco". Historia Mexicana, vol. 28, núm.1, 24-61.

Leal Maldonado, Jesús, y García-Bellido García de Diego, Javier (2003) "Y el desarrollo universal de la ciudad excluida". Ciudad y Territorio: Estudios Territoriales, núm. 136-137, 249-255.

Lira, Luis (2006) "Revaloración de la planificación del desarrollo". Serie Gestión Pública CEPAL-ONU, núm. $59 . \quad$ [URL: $<$ http://www.eclac.cl/publicaciones/xml/7/26977/sgp59.PDF>. Consultado el 15 de Enero de 2015].

Mancuso, F. (1980) Las Experiencias del Zoning. Barcelona: GG.

Mesa A., Manuel (1961) "Proceso y situación actual de la reforma agraria". Historia Mexicana, vol. X, núm. 3, 439-460. 
Meza Ramos, Eduardo (1987) Corporativismo estatal y movimiento urbano popular en Tepic (1970-1987). Tesis de licenciatura inédita en la Universidad Autónoma de Nayarit, Tepic.

Mendieta y Núñez, Lucio (1946) El problema agrario de México. México: Porrúa. Mendoza, A. (2002) Historia y Narrativa en el ejido de San Francisco Uruapan (1916-1997). Zamora: El Colegio de Michoacán.

Moctezuma, Pedro (1985-1986) "La CONAMUP”. Estudios Políticos, vols. 4-5, núms. 4-1, 30-37.

Montalvo Ortega, Enrique (1988) "Política agraria y movilización campesina después de la revolución", en Historia de la cuestión agraria mexicana. México: Centro de Estudios Históricos del Agrarismo en México, Siglo XXI, tomo III, 107-135.

Moreno Valle, Javier (1979) "Apuntes para una historia de la planeación en México". Revista de Administración Pública, núm. 39, 45-60. [URL: $<$ http://www.juridicas.unam.mx/publica/librev/rev/rap/cont/39/pr/pr5.pdf $>$. Consultado el 21 de Junio de 2014].

Portilla, Jorge (1984) Fenomenología del relajo y otros ensayos. México: FCE.

Pazos, Luís (1991) La disputa por el Ejido. México: Diana.

Ramírez Saiz, Juan (1992) "Los objetivos de la Ley General de Asentamientos humanos (LGAH)", en G. Garza (coord.) Una década de planeación urbanoregional en México, 1978-1988. México: El Colegio de México, 27-53.

Rivera M., Guadalupe (1983) La propiedad territorial en México 1301-1810. México: Siglo XXI.

Roch, Fernando (2002) "Agentes sociales y tendencias urbanísticas: hegemonía inmobiliaria y pérdida de urbanidad". Boletín $C F+S$, núm. 29/30. [URL: $<$ http://habitat.aq.upm.es/boletin/n29/afroc1.html $>$. Consultado el 12 de Febrero de 2015].

Robles, Reynaldo (1993) El Municipio. México: Porrúa.

Sánchez, G. (2008) Planeación moderna de ciudades, México: Trillas-UAM.

SEDESOL (2001) Programa Nacional de Desarrollo Urbano y Ordenación del Territorio 2001-2006, Resumen Ejecutivo. México: Secretaría de Desarrollo Social (SEDESOL).

[URL: $<$ http://www.ordenjuridico.gob.mx/Publicaciones/CDs2010/CDMetropolitano/p df/DOC11.pdf $>$. Consultado el 23 de Octubre de 2014].

Ugalde, Vicente (2010) "La coordinación institucional del ordenamiento territorial en México". Norte Grande, núm. 47, 105-120. [URL: $<$ http://www.scielo.cl/pdf/rgeong/n47/art06.pdf $>$. Consultado el 24 de Enero de 2015].

Villar Calvo, Alberto (1998) La impotencia municipal en el ordenamiento urbano: herencia del centralismo y la subordinación: caso de estudio, Estado de México. México, D.F.: Universidad Autónoma del Estado de México. 
Wallerstein, Inmanuel (1998). Impensar las ciencias sociales: límites de los paradigmas decimonónicos. México: Siglo XXI.

Wolf, Erick R. (1985) Las luchas campesinas del siglo XX. México: Siglo XXI.

Warman, Arturo (1980) Los campesinos, hijos predilectos del régimen. México: Editorial Nuestro Tiempo. 